\title{
Land in the Arctic.
}

THE study of the Arctic tides attracted wide attention when Harris concluded from his stationary wave-theory in 1911 that an extensive area of land existed within the unexplored area of the Arctic regions. Nansen, on the contrary, inferred the existence of a deep Polar basin from his observations in the Fram between 1893 and 1896.

Harris's hypothetical land gave a stimulus to explorers, but their search was fruitless. Stefanson, on his remarkable journeys over the sea-ice north of Alaska, and McMillan on this Crocker Island expedition, both touched the outskirts of the unknown region without finding anything but broken sea-ice. Amund. sen in 1926 passed over the central part of the unexplored region in the dirigible Norge without seeing any land. Between 1918 and 1925 the Maud expedition made numerous tidal observations in the area north of Siberia. These observations, combined with earlier data, have been critically examined by Sverdrup and indicate in this area a tidal wave of the progress ive type, differing from the stationary type deduced by Harris; nor do they indicate the existence of any ex.

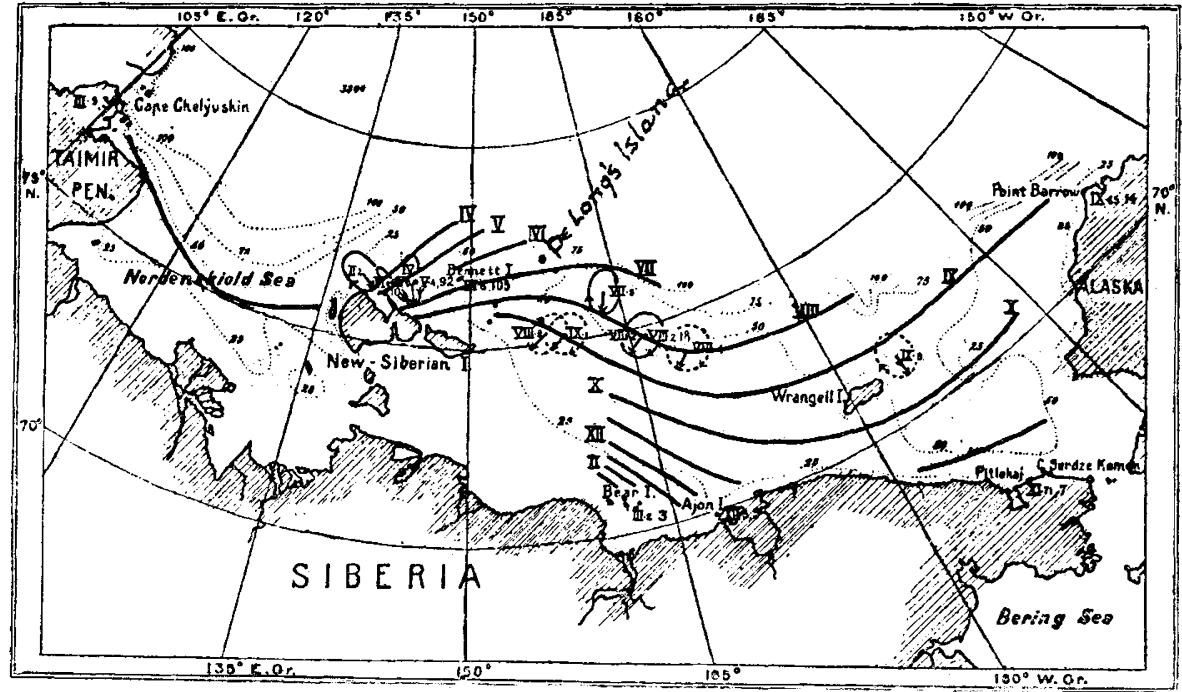

FI*. 1.-Tiral observations and co-tidal lines at spring tide on the north siberian shelf.

it reaches Point Barrow, although the direct distance from the Spitsbergen opening to the Island and to Point Barrow is nearly the same. This suggests a shallow sea in the unexplored region north of Wrangel Island and Point Barrow, with perhaps islands in places.

The tidal streams met with were of the rotary type usual in open ocean areas, but they present a striking peculiarity. Below the ice to a depth of some twenty fathoms water of the same density is present, while below this there is a sudden increase in density and tensive masses of land within the unexplored region.

The illustration here reproduced (Fig. 1) from Sverdrup's papers ${ }^{1}$ shows the cotidal lines (the times of high water, in terms of Greenwich lunar time at full and new moon), and indicates that the progressive tidal wave from the north Atlantic enters the opening between Greenland and Spitsbergen and crosses the Arctic Sea without meeting any obstruction caused by extensive land masses. The figure reveals that the tidal wave reaches De Long's Island five hours before

1 “"The Tides on the North Siberian Shelf: their Bearing on the Existence of Land in the Arctic Sea and their Dynamics," H. U. Sverdrup, Journal of the Washington Academy of Sciences, vol. 16 p. 529-540 (Washington, Dec. 1926). later a slow increase on approaching the bottom. In the water layer of equal density the tidal streams ran slow, but in the layer where density increased rapidly with depth the tidal streams were at a maximum, dying away towards the bottom.

The water can be considered as composed of three layers of different eddy-viscosity. In the upper layer of equal density vertical eddies are free to be developed and the eddy-viscosity or 'virtual' viscosity is great. vertical motion is restrained and the eddy-viscosity is low, while below this, where there is a slower increase in density, the eddy-viscosity is of an intermediate value.

H. W. H. In the intermediate layer of rapidly changing density

\section{The Initial Phase in Gaseous Explosions.}

W HILE an atmosphere of controversy is not perhaps the best for the calm interpretation of scientific facts, there is no doubt that the clash of opinions gives a zest to research and sometimes speeds up discovery. The slow uniform movement of flame in the initial phase of the explosion of gases-first studied by Le Chatelier - has given rise to such a controversy between Prof. W. A. Bone and his colleagues at the Imperial College of Science and Technology, South Kensington, and Prof. R. V. Wheeler and his colleagues at the Safety in Mines Research Laboratories at Sheffield.

There is no doubt that many explosive mixtures, when lighted at the open end of a long tube, burn with a slow uniform movement for a certain distance, and as a rule this uniformity is more marked the slower the propagation of the flame. When 'limit' mixtures of various saturated hydrocarbons with air, i.e. mixtures which would just propagate flame, were ignited at the open end of a tube, Prof. Wheeler and his colleagues found that the flame had an initial uniform movement which was the same for each mixture; and, moreover, when any two of these mixtures were mingled together, the complex was also a 'limit' mixture and burnt at the same rate. So far, we understand, the speed-law is unquestioned. But when the law is extended to non-limit mixtures and to all gaseous mixtures of the same type (i.e. with either excess of combustible or excess of oxygen), which have the same uniform speed of flame, the two schools are in disagreement. Prof. Bone (with Messrs. Fraser and Winter) has just published in the Proceedings of the Royal Society photographs of the flames initiated in ethylene-oxygen, acetylene-oxygen, and in hydrogen-oxygen mixtures. He finds that such fast-burning mixtures do not always show any

No. 3003, VoL. 119] 